\title{
INCREASED SOLUBLE ST2 CONCENTRATION IN NEONATES WITH CONGENITAL DIAPHRAGMATIC HERNIA AND PULMONARY HYPERTENSION RECEIVING ECMO SUPPORT
}

\begin{abstract}
Florian Kipfmueller ${ }^{1}$, Lukas Schroeder ${ }^{1}$, Heiko Reutter ${ }^{1}$, Andreas Mueller ${ }^{1}$, Stefan Holdenrieder ${ }^{2}$
1 Department of Neonatology and Pediatric Critical Care Medicine, Children's Hospital, University of Bonn, Germany 2 Institute for Clinical Chemistry, University Hospital Bonn, Germany
\end{abstract}

\section{Background:}

Pulmonary hypertension $(\mathrm{PH})$ is one of the most important determiners of mortality in neonates with congenital diaphragmatic hernia $(\mathrm{CDH})$. $\mathrm{PH}$ can be assessed by echocardiography but knowledge on potential biomarkers is scarce. Soluble ST2 (SST2) is released by cardiomyocytes experiencing mechanical stress and has been extensively investigated as a cardiac biomarker in the adult population and to some extend in children.

Aim of our study was to investigate the expression of SST2 in CDH newborns receiving ECMO support compared to patients without ECMO.

\section{Methods:}

$30 \mathrm{CDH}$ newborns were prospectively enrolled. SST2 concentration was measured from EDTA-Plasma (Quantikine, R\&D Systems, Abingdon, UK) at the age of $0,6,12,24,48$ hours and 7-10 days of life and was compared in $\mathrm{CDH}$ newborns with and without ECMO support.

Table 1: Baseline characteristics:

\begin{tabular}{|l|l|l|l|}
\hline Variables & CDH ECMO & CDH Non-ECMO & p-value \\
\cline { 2 - 4 } & $\mathrm{n}=11$ & $\mathrm{n}=19$ & \\
\hline Demographics & & & 0.163 \\
\hline Gestational age, weeks & $37.0(33.9-38.7)$ & $38.1(34.0-40.0)$ & 0.537 \\
\hline Birth weight, $\mathrm{kg}$ & $2.7(1.7-3.52)$ & $3.0(1.9-3.6)$ & 0.670 \\
\hline Umbilical artery $\mathrm{pH}$ & $7.34(7.23-7.38)$ & $7.34(7.17-7.42)$ & $\mathbf{0 . 0 2 5}$ \\
\hline o/e LHR, \% & $36(16-50)$ & $42(34-60)$ & 0.232 \\
\hline Left-sided CDH, $\mathrm{n}$ & $8(73 \%)$ & $19(100 \%)$ & $\mathbf{0 . 0 1 8}$ \\
\hline Intrathoracic liver, $\mathrm{n}$ & $8(73 \%)$ & $4(21 \%)$ & 0.402 \\
\hline FETO, $\mathrm{n}$ & $2(18.2 \%)$ & 0 & $<\mathbf{0 . 0 0 1}$ \\
\hline SNAP-II Score & $42.5(16-76)$ & $5(0-26)$ & \\
\hline
\end{tabular}

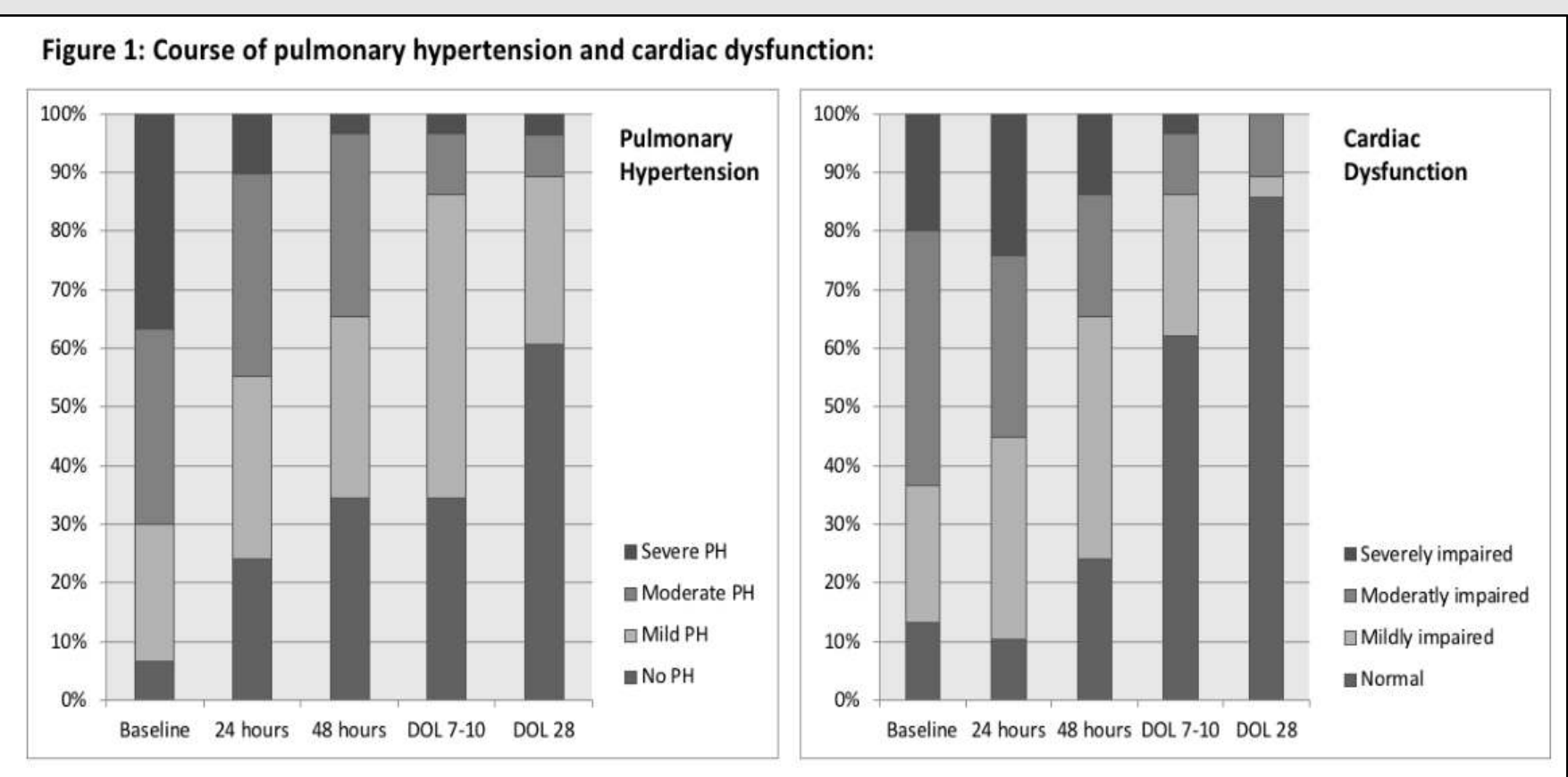

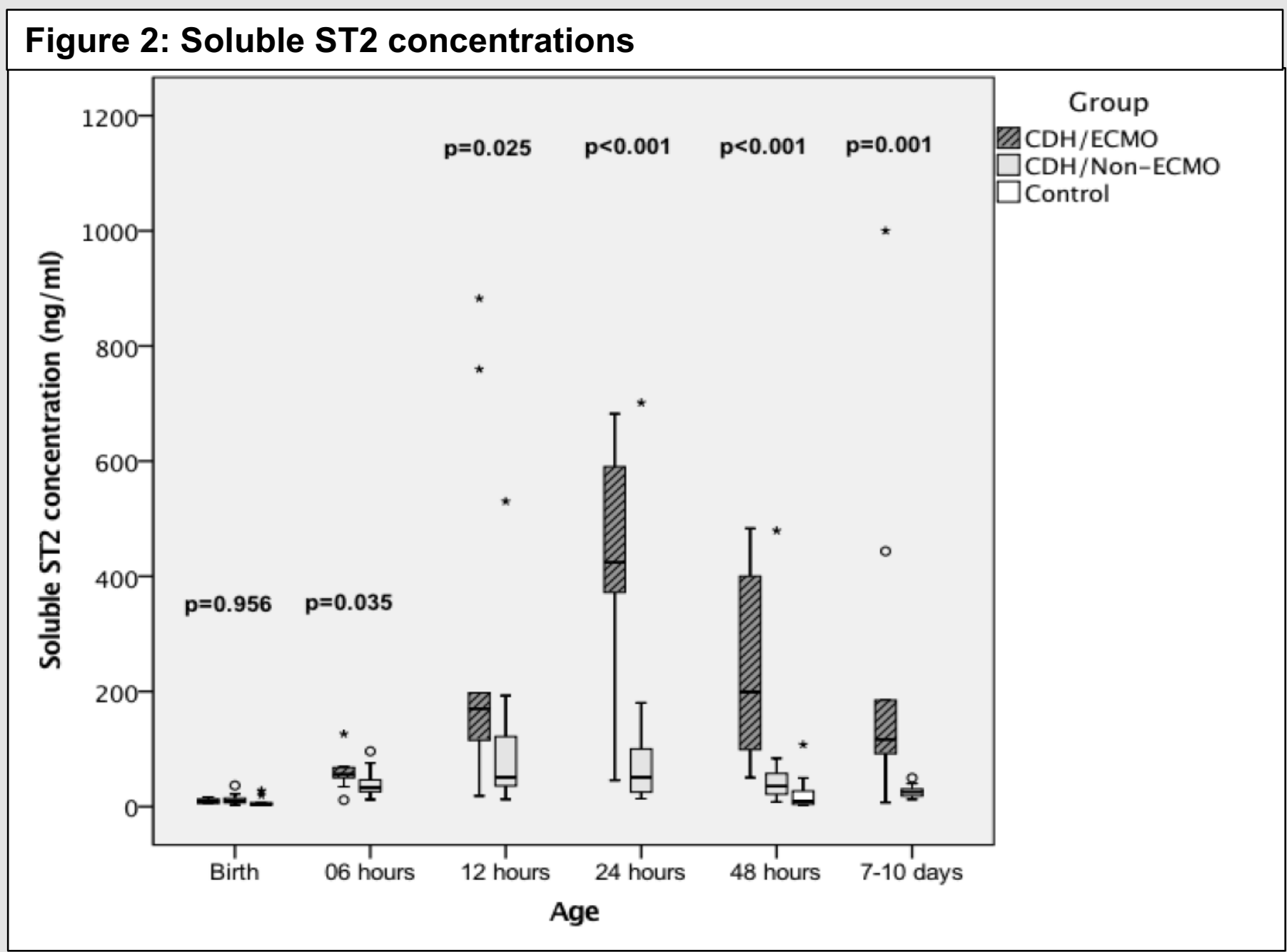

Results:

$11 / 30$ patients were allocated to the ECMO group and $19 / 30$ to the non-ECMO group. Baseline characteristics are demonstrated in table 1 and the severity of $\mathrm{PH}$ and cardiac dysfunction are demonstrated in figure 1 . The concentration of SST2 was significantly higher at 6,12 , 24, 48 hours and at 7-10 days in the ECMO group (Figure 2).

At 6 hours the optimal cutoff to predict ECMO was $48.0 \mathrm{ng} / \mathrm{ml}$ (AUC $0.742 ; p=0.035$ ) with a sensitivity of $80 \%$, and a specificity of $78.9 \%$ (Positive predictive value: $66.7 \%$, Negative predictive value: $88.2 \%$ ). At 12 hours the cutoff for SST2 to predict ECMO was $112 \mathrm{ng} / \mathrm{ml}$ (AUC $0.766 ; p=0.025$ ) (sensitivity of $77.8 \%$, specificity $73.7 \%$, PPV $58.3 \%$, NPV $87.5 \%)$

sST2 correlated significantly with $\mathrm{PH}$ severity at $6 \mathrm{~h}(\mathrm{r}=0.597, \mathrm{p}=0.001)$, $12 \mathrm{~h} \quad(\mathrm{r}=0.616, \quad \mathrm{p}<0.001)$ and $24 \mathrm{~h}(\mathrm{r}=0.720, \quad \mathrm{p}<0.001), 48$ hours $(r=0.720, p<0.001)$, and $7-10$ days $(r=0.466, p=0.016)$.

\section{Discussion:}

We observed significantly higher sST2 concentrations in CDH newborns receiving ECMO. Additionally, sST2 correlated well with $\mathrm{PH}$ severity and cardiac dysfunction. ST2, measured early after birth, is associated with the need for ECMO. Due to the low mortality rate in our study (4/30), we did not correlate SST2 concentration with mortality. Future studies should further investigate the predictive information derived from sST2 measurements in $\mathrm{CDH}$ newborns, especially in regards of mortality, need for ECMO and persistence and severity of $\mathrm{PH}$ and cardiac dysfunction.

\section{Conclusion:}

Soluble ST2 expression differed significantly in CDH newborns according to disease severity and might be a potential parameter to assess risk for ECMO and cardiovascular compromise in this population. 